Place-Based Food Systems Keynote Address

\title{
hishuk'ish tsawalk-Everything is one. Revitalizing place-based Indigenous food systems through the enactment of food sovereignty
}

PLACE-BASED FOOD SYSTEMS CONFERENCE: Making the Case, Making it Happen August 9-10th, 2018

\author{
Charlotte Coté * \\ University of Washington
}

Submitted October 2, 2019 / Published online October 31, 2019

Citation: Coté, C. (2019). hishuk'ish tsawalk_-Everything is one. Revitalizing place-based

Indigenous food systems through the enactment of food sovereignty. Journal of Agriculture,

Food Systems, and Community Development, 9(Suppl. 1), 37-48.

https://doi.org/10.5304/jafscd.2019.09A.003

Copyright (C) 2019 by the Author. Published by the Lyson Center for Civic Agriculture and Food Systems. Open access under CC-BY license.

$\mathrm{M}$ y name is Charlotte. My traditional name is thlutismayulth, Carrying Thunder, from our whaling heritage. I'm going to talk a little about who I am and where I am from. I am from the

\section{Note}

This paper is adapted from Dr. Coté's keynote address on August 10, 2018, entitled hishuk'ish tsawalk - Everything is One. Revitalizing Place-Based Indigenous Food Systems through the Enactment of Food Sovereignty, given at the Place-Based Food Systems Conference that was hosted by the Institute for Sustainable Food Systems at Kwantlen Polytechnic University. The conference brought together community and academic leaders to share research and practice and to foster effective collaboration. More information is at https://www.kpu.ca/pbfs2018

* Dr. Charlotte Coté is associate professor in the Department of American Indian Studies at the University of Washington. She is also the president of the Seattle-based, Native-led nonprofit organization the Potlatch Fund.

Dr. Coté is from the Nuu-chah-nulth community of Tseshaht on the west coast of Vancouver Island. She has dedicated her personal and academic life to creating awareness around Indigenous health and wellness issues and has taken an
Tseshaht Nation, one the 14 groups that make up the larger Nuu-chah-nulth Nation on the west coast of Vancouver Island.

Before I begin, I want to pay respect to the

active role in working with Indigenous peoples and communities in addressing health disparities through decolonization strategies and the enactment of food sovereignty centered in the revitalization of traditional foodways and ancestral ecological knowledge.

Dr. Coté is the author of Spirits of Our Whaling Ancestors. Revitalizing Makah and Nun-chab-nulth Traditions. Her forthcoming book is $U u$-a-thluk (taking care of): Revitalizing Indigenous Foodways and Ancestral Ecological Knowledge. Restoring Health and Wellness in Northwest Coast Native Communities.

Dr. Coté is founder and chair of UW's “"The Living Breath of wəłəb?altx ${ }^{w}$.' Indigenous Foods and Ecological Knowledge" Symposium, which focuses on topics such as Indigenous foodways and ecological knowledge, Tribal food sovereignty and security, traditional foods and medicines, health and wellness, environmental justice, treaty rights, and climate change. Dr. Cóte can be contacted at the Department of American Indian/Native American Studies, University of Washington, Box 354305; Seattle, WA, 98195 USA; clotise@,uw.edu 
First Peoples of this land, the Coast Salish peoples. Every time we enter these territories-unceded, recognized traditional territories-we need to acknowledge not just the people, the elders, and the leaders, but also the ancestors whose spirits still walk in these spaces. So, I acknowledge that before I begin.

The material in this talk comes from a book I have been working on for quite a few years since I published my last book.

So, who we are. The Nuu-chah-nulth are on the west coast of Vancouver Island. The traditional territory of the 14 nations also includes the western tip of western Washington, because the Makah in western Washington are our relatives (Figure 1). It was the border that separated us, but we are recognized as relatives and share the same language, the same traditions, and the same whaling heritage.

I want to show a couple of minutes of this video, nuučaanuulathin We Are Nuu-chah-nulth, produced by Nitanis Desjarlais and John Rampanen. ${ }^{1}$ John Rampanen is a member of the Tla-o-qui-aht First Nation, one of the Nuu-chah-nulth Nations, and he and his wife created this film. His wife is Cree and has lived in our community for quite a few years.
Our day begins with an expression of gratitude for the gift of life that we've been provided. We trace our roots back to our origins. The first breath. The first steps taken upon these lands. The wisdom and strength of our ances- tors courses through our veins, passed from genera- tion to generation. With care and gentleness, we carry forth our obligation to add to these teachings and pass them along to the next generations, so that they may walk, gently upon

this land and thrive. Our way of life was crafted through thousands of years of connecting with our lands and waters. We recognize that all life is precious and contains a spirit, and none are superior or inferior to another. Our life stems from the abundance of the ocean and land. We have established some expertise in harvesting foods and medicines and other day-to-day materials to live a comfortable life. We are the people of the ocean. We are a whaling society. We are warriors and healers. Our nations are many, and we live along every inlet, harbor, river and stream along the western coast of this great island. Our hereditary chiefs and their advisors maintain stewardship over our lands and ensure that our protocols and laws are followed, so that future generations may share in the abundance of our territories.

—nuičaanuutath in We Are Nuu-chah-nulth, Desjarlais \& Rampanen, 2015

I just wanted you to see a little of that video because it really nicely shows our connection to our homelands. Since we're talking about placebased food systems, it's important to situate, to

Figure 1. Nuu-chah-nulth Ha-houthee (Ancestral Lands and Waters)

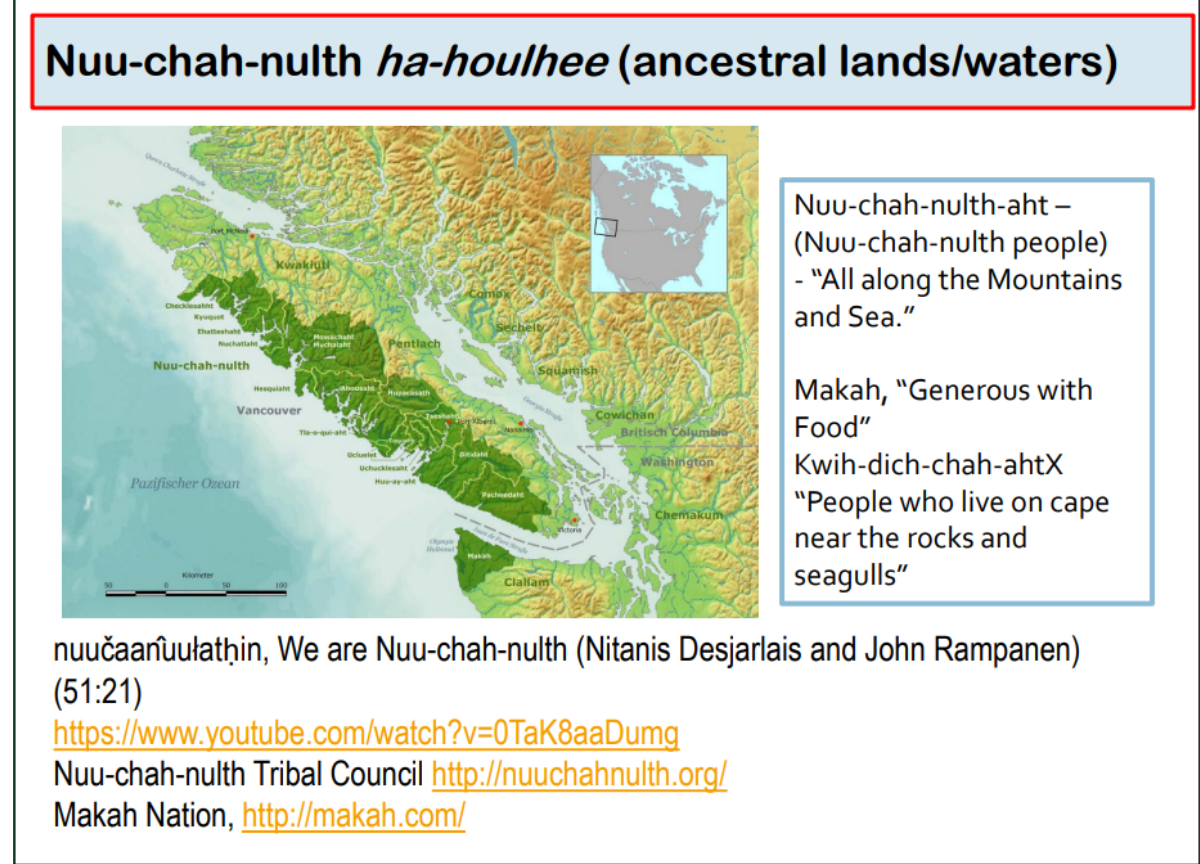

${ }^{1}$ See the video at https://www.youtube.com/watch?v $=0 \mathrm{TaK} 8 \mathrm{aaDumg}$ 
position, my talk in that framework.

So, I am from the Tseshaht First Nation. It's one of the central groups that is part of the larger Nuu-chah-nulth Nation. Our traditional territory was in the Broken Group Islands, but following colonization, we were pushed up the Alberni Canal into an area that was our winter village just outside of the city of Port Alberni. The town hasn't grown since I've been there; 20,000 people. We were created on what has become known as Benson Island; there is a little spot on that island where our elders bring us, and we walk to that spot, and they tell us that's exactly where we were created. The area is called Ts'ishaa, so Tseshabt is the people of 'Ts'ishaa. Ts'ishaa literally translates to the place that reeks of whale remains.

And so, we're The-Place-That-Reeks-OfWhale-Remains people. That's connecting us to the whaling heritage.

I'm going to begin with a quote as I start into this presentation:

Children, language, lands: almost everything was stripped away, stolen when you weren't looking because you were trying to stay alive. In the face of such loss, one thing our people could not surrender was the meaning of land. In the settler mind, land was property, real estate, capital, or natural resources. But to our people, it was everything: identity, the connection to our ancestors, the home of our nonhuman kinfolk, our pharmacy, our library, the source of all that sustained us. Our lands were where our responsibility to the world was enacted, sacred ground. It belonged to itself; it was a gift, not a commodity, so it could never be bought or sold. (Kimmerer, 2013, p. 17)

This quote is from a well-known ethnobotanist, a Potawatomi scholar, Dr. Robin Wall Kimmerer. Have any of you heard of Dr. Kimmerer? If you have never read her book [Braiding Sweetgrass] and you believe in these connections to our lands, to our waters, to everything around us, to the environment, you have to read it. It's one of the most amazing books I have ever read. In this book, she summons readers to imagine a different relationship with the land, the waters, with the plants and animals, and to rebuild a sustainable relationship where people and animals, plants, the environment are good medicine for each other, and so she writes:

In the indigenous worldview, a healthy landscape is understood to be whole and generous enough to be able to sustain its partners. It engages the land not as a machine but as a community of respected, non-human persons to whom we humans have a responsibility. Reconnecting people and the landscape is as essential as re-establishing proper hydrology or cleaning up contaminants. It is medicine for the Earth. (Kimmerer, 2013, p. 338)

Indigenous peoples and communities worldwide have experienced a series of traumatic invasions that have resulted in long-lasting and disastrous outcomes. Massacres, genocidal policies, disease pandemics, forced removal and relocation, Indian boarding schools, assimilation policies, and prohibition of spiritual and cultural practices have produced a history of ethnic and cultural genocide. Many of the health issues and socioeconomic inequalities indigenous people face today can be linked directly to colonization through the brutal disposition of homelands, through globalization and migration, forced in many cases, and culture and language loss.

Beginning in the 1970s, indigenous peoples began focusing on self-determination and decolonization strategies through the restoration and revitalization of cultural traditions, language revitalization, and implementation of our own education, social and child welfare programs. These efforts were centered in a movement toward actively shaping, nurturing, and fostering culturally, spiritually, and emotionally healthy and sustainable communities. The boarding school system had a profound effect on our health, whereby indigenous children were not just removed from their families, communities, language, and culture, but were removed from their traditional foods. They were fed processed foods laden with salt, sugar, and fat. Today, we indigenous peoples face the highest rates of food-related diseases, such as type 2 diabetes, cardiovascular disease, hypertension, autoimmune 
disease, and obesity - more than any other racial or ethnic group in Canada and the United States. These diseases are at epidemic levels, making autonomy over our indigenous homelands crucial to our very survival as people. As part of the decolonization movement, we are recognizing the need to decrease our dependence on the globalized food system and revitalize our indigenous placebased food systems and practices. We must do this through the reaffirmation of a physical, emotional, and spiritual relationship that we have to the lands, waters, plants, and all living things that sustain our communities and cultures.

The last 30 years have seen an increase in the globalization of food systems through neoliberal state policies that place decision-making authority over food production and distribution in the hands of national, state, supranational, and transnational organizations promoting agricultural practices that do little to alleviate world hunger. The overcommodification of food after World War II resulted in concentrating the decision-making power over food, land, and seas in the hands of only a few. Policy development regulated food to meet the demands of the agribusiness industry (Patel, 2009; Trauger, 2015; Wittman, Desmarais, \& Wiebe, 2010).

This neocolonial process impoverished millions of indigenous peoples by displacing them from their homelands, resulting in many of them being forced into wage labor to serve the global food economy. In 1993, small-scale farmers' organizations formed La Via Campesina, and since then this global agrarian movement, representing 182 organizations from 81 countries (La Via Campesina, n.d.), has become the strongest voice in radical opposition to the globalized neoliberal model of agriculture and food production. In 1996, La Via Campesina challenged the state-led food security movement, asserting that it did little to end global hunger, and introduced a new global food review concept: food sovereignty. La Via Campesina established 11 principles that were integrated into its position on food sovereignty and presented at the World Food Summit in Rome in November 1996 (La Via Campesina, n.d.). The meaning of food sovereignty was further developed in various forums and meetings, and, in 2007, at an international forum on food sovereignty in Mali, a definition was articulated that has become the one most cited:

Food sovereignty is the right of peoples to healthy and culturally appropriate food produced through ecologically sound and sustainable methods, and their right to define their own food and agricultural systems. It puts the aspirations and needs of those who produce, distribute and consume food at the heart of food systems and policies rather than the demands of markets and corporations. (Declaration of Nyéléni, 2007, para. 3)

This notion of food sovereignty became a uniting call to small-scale farmers and indigenous peoples throughout the world. While this movement developed in an agrarian-based Latin American context, indigenous peoples with fishing, hunting, and gathering traditions were able to connect to its underlying philosophy: All nations, including indigenous nations, have the right to define strategies and policies, and develop food systems and practices, that reflect their own cultural values around producing, consuming, and distributing food. Indigenous peoples in Canada and the United States began exploring ways that food sovereignty could be both defined and deployed as a concept in creating dialogue and action around the revitalization of indigenous food practices and ecological knowledge.

In British Columbia, the Working Group on Indigenous Food Sovereignty (WGIFS) was created in 1996, and was one of the first indigenous groups to explore the new concept of food sovereignty. Through meetings, forums, workshops, and discussion groups, the WGIFS brought together indigenous elders, traditional harvesters, and community members who developed four main principles of indigenous food sovereignty to frame and guide this new indigenous food sovereignty movement. These principles are:

(1) Sacred sovereignty, that food is a sacred gift from the creator.

(2) Participatory, that it is a call to action and that people have a responsibility to uphold 
and nurture healthy and interdependent relationships with the ecosystem that provides the land, water, plants, and animals as food.

(3) Self-determination, that food sovereignty needs to placed within a context of indigenous self-determination with the freedom and ability to respond to community needs around food.

(4) Policy, to provide a restorative framework for reconciling indigenous food and cultural values with colonial laws and policies. (Morrison, 2011, pp. 100-101)

I argue and assert that indigenizing this food sovereignty movement means moving it beyond a rights-based discourse to emphasize cultural responsibilities and relationships that indigenous peoples have with their environment. This also requires examining the efforts being made by indigenous communities to strengthen their placebased food systems and restore these relationships through the revitalization of our own indigenous foods and ecological knowledge as we assert control over our own well-being.

Indigenous peoples are united in cultures that are embedded and shaped by deep and meaningful relationships to the land, waters, plants, and animals that have sustained our cultures. While indigenous communities are distinct, making it impossible to define food sovereignty in a way that reflects all of our cultures, WGIFS Director Dawn Morrison says we are united by eco-philosophical principles that have guided indigenous people's interactions with the environment and the nonhuman world that has informed our food systems. This philosophical understanding, Morrison asserts, is antithetical to the relationship that Western society has with the environment. She writes, "in the Eurocentric belief ... humans are to dominate and control nature, and therefore seek to 'manage' the land that provides us with our food. Indigenous eco-philosophy reinforces the belief that humans do not manage land, but instead can only manage our behaviours in relation to it" (Morrison, 2011, p. 99).

Indigenous food sovereignty weaves together the theoretical and analytical strands that many indigenous scholars such as Taiaiake Alfred, Jeff Corntassel, Robin Kimmerer, and others have explicated regarding indigenous people's relationship to the natural world, and which was weakened by colonialism, neoliberalism, displacement, and capitalism. Thus indigenous food sovereignty is defined within a restorative context that works to nurture individual and community health by repairing and fostering these healthy relationships.

Placed within the context of selfdetermination, indigenous food sovereignty as a concept aligns with principles developed by Cherokee scholar Jeff Corntassel (2008) in his notion of sustainable self-determination. Corntassel positions responsibilities and relationships at the core of indigenous self-determination. In order to de-colonize, he contends, indigenous peoples need to direct change from within and through action and policy toward becoming sustainable, selfdetermining nations. Corntassel maintains that the existing rights discourse can only take indigenous peoples so far. The rights-based framework to date emphasizes the sovereign state-political and legal recognitions of indigenous rights - which ignores the cultural responsibilities and relationships indigenous peoples have with their environments, and that have sustained their cultures. Within a sustainable self-determination framework, the emphasis is placed on de-colonization and restoration that connect political autonomy, governance, the environment, and community health. For indigenous peoples, sustainability is intrinsically linked to the transmission of traditional knowledge and cultural practices to future generations. Without the ability of community members to continually renew their relationships with the natural world, through practices such as gathering medicines, hunting and fishing, basketweaving, speaking our indigenous languagesteachings that are core cultural values-all of these will be jeopardized.

Corntassel's (2008) notion of sustainable selfdetermination and the WGIFS's definition of indigenous food sovereignty emphasize responsibility, mutuality, kinship, and relationships. This is what Kimmerer (2013) calls "cultures of reciprocity." She writes: 
Humans and non-humans are bound to each other in a reciprocal relationship that creates duties and responsibilities. Just as all beings have a duty to me, I have a duty to them. If an animal gives its life to feed me, I'm in turn bound to support its life. If I receive a stream's gift of pure water, then I am responsible for returning a gift in kind. An integral part of a human's education is to know those duties and how to perform them. (p. 115)

The human-ecosystem relationship is characterized as one of reciprocity and respect, where humans do not control nature but live in harmony with it. Restoring the health of indigenous communities means restoring the health of the land, or as Kimmerer (2013) so aptly states, "We restore the land, and the land restores us" (p. 336).

So, today, my people, the Tseshaht and the larger Nuu-chah-nulth Nation, are actively engaging in de-colonization and sustainable selfdetermination through reinstatement of authority over our ha-houthee (our ancestral territory), and through the development of strategies and implementation of policies aimed at the sustainable production and consumption of traditional foods through an ecologically sound, place-based food system that honors our sacred relationships to the land, water, plants, and all living things. We have philosophies that guide this work that we are doing, and we place these within important strategies that we're working through, in developing sound economic programs, and also in the kind of the work we're doing individually within our communities. We follow these principles, and I just wanted to go through them before I show some of the work that we're doing, and specifically work that I've been doing with some people in my community.

Embodied in the Nuu-chah-nulth philosophy of iisaak, which literally translates to "respect," uua-thluk, which means "taking care of" or "taking care of the ba-houthee," our ancestral homelands, and hishuk'ish tsawalk, literally translated to "everything is one" but means "everything is connected," is the understanding that we must keep and honor the wisdom and values of ancestral knowledge in maintaining responsible and respectful relationships with the environment. Nuu-chah-nulth-aht or Nuu-chah-nulth people are raised with the understanding of iisaak, which applies to all life forms as well as the land and the water. Iisaak is about a most basic understanding, which teaches that all life forms are equal, that they all are held in equal esteem. Our relationships to the plants and animals that give themselves to us as food derive from this notion of iisaak, which enforces sustainability and places sanctions on those who are stingy or those who are wasteful (Turner, Ignace, \& Ignace, 2000). The vision of uu-a-thluk is to take care of, especially take care of the ha-bouthee in a way that's consistent with Nuu-chah-nulth values and principles of responsibility given to us by our creator, N'ass. These principles of iisaak and uu-athluk are embedded within this overarching philosophy of hishuk'ish tsawalk, everything is one.

Have any of you read any of Chief Umeek's work? He wrote a couple of books, has a background in education, and is one of the first indigenous scholars in this area to really look at core principles or philosophies of an indigenous nation and think through them within a context of philosophical meanings, and how you can use those philosophical meanings and apply them in a modern-day society. He looks at these meanings, especially hishuk'ish tsawalk, in his book Tsawalk: A Nun-chah-nulth Worldview. Here he introduces us to this indigenous worldview and ontology drawn from the Nuu-chah-nulth origin stories and includes a lot of stories in this book.

Within the Nuu-chah-nulth worldview, Chief Umeek explains that the universe is regarded as a network of relationships. Hishuk'ish tsawalk represents the unity of the physical and metaphysical in a relationship embodied in the principle of iisaak. This philosophy connects people, animals, plants, and the natural and the supernatural or spiritual realms in a seamless and interconnected web of life where all life forms are revered and worthy of mutual respect. The land, water, animals, and plants are regarded as your kinfolk, not as a commodity that can be exploited. The stewardship of our homelands was embedded in this philosophy that Chief Umeek articulates in his book, and this is what we are striving to revitalize. 
So, I want to now look at and share with you some of, what I would say, is reconnecting us to our place-based food system. to be be honest, I've never used the term "place-based food systems" until this conference. I mean, we just know the work we're doing, and that our foods are placebased.

\section{Revitalizing our Place-Based Food Systems}

\section{Makah Whale Hunt}

How many of you heard of the Makah whale hunt in Western Washington? It's very controversial to some people, with many people not realizing why the Makah had decided to revitalize that one aspect of their larger tradition - a whaling tradition in which the hunt is one part. There was so much controversy over it, that when I was a graduate student in 1994 and the Makah made a decision they're going to revitalize their hunt, I decided I needed to write about this. I wrote my dissertation on the revitalization of whaling because, following the announcement by the Makah, we also, the Nuu-chah-nulth and specifically Tseshaht, were talking about revitalizing our whale hunts as well. Against a lot of opposition, I think misdirected in

Figure 2. The 1999 Makah Harvest of Maa'ak

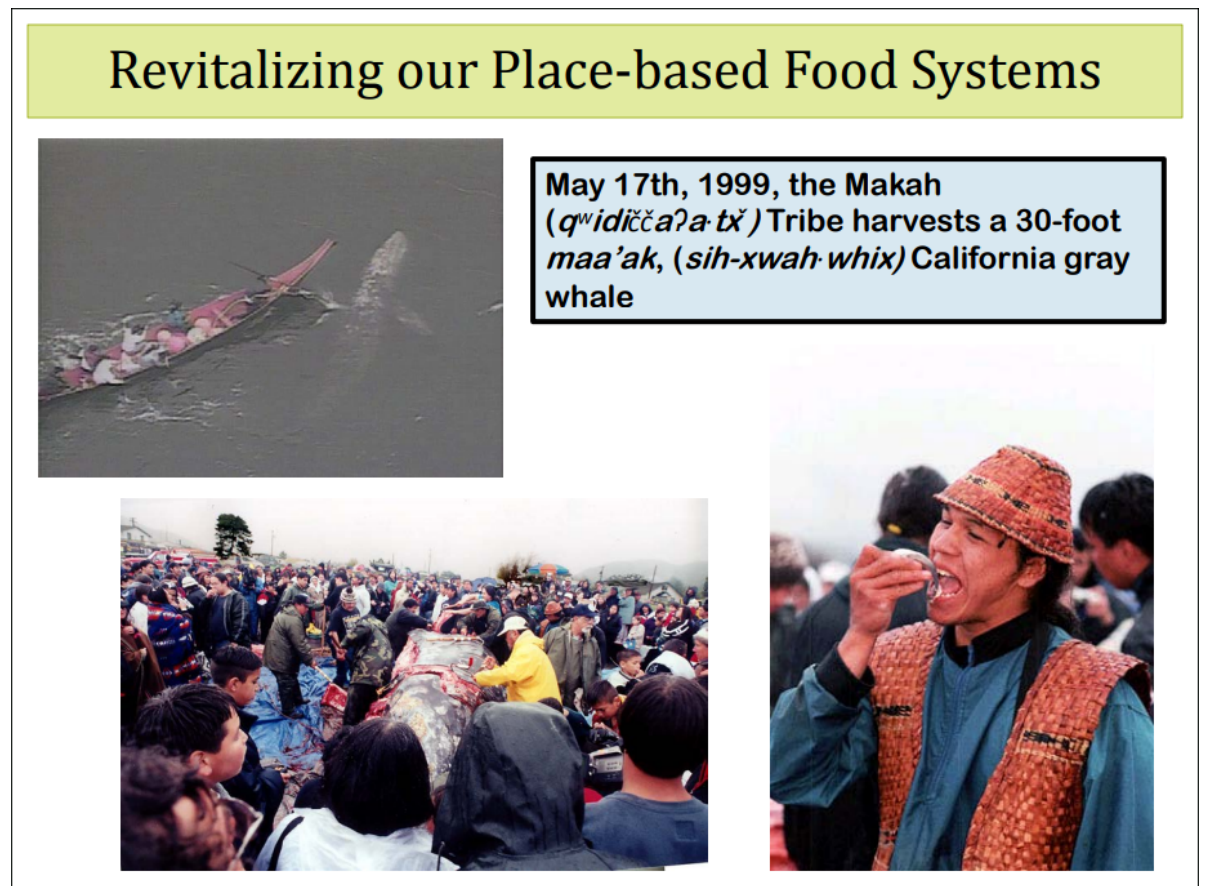

many ways, the Makah in 1999 were able to harvest maa'ak, in our language, the Californian grey whale, or sib-xwah-wbix in their language (Figure 2).

The Makah, or the Kwih-dich-chuh-ahtx people, revitalized a very important connection to their place-based food system. And we have to think beyond place-based, meaning land; for the West Coast peoples we have a marine-based culture and marine-based economies, and our sustenance comes from the waters. So, many people look at mapping or geography, look at land as substance, water as void. In our cultures, the water is the substance, the land is void. So, for the Makah to restore their whale hunts in 1999 was significant to reconnecting to that major aspect of their cultures and to their identities. The Makah, as well as the Nuu-chah-nulth, are recognized as whaling people, and we're the only people who culturally whaled on the West Coast until you get up into Alaska and northern Canada, where there are strong whaling cultures as well.

\section{Tseshaht Communal Fish Days}

I grew up with our communal fish days. We still have these community days where we gather on Sundays to come together and fish (Figure 3). We begin fishing at $5 \mathrm{AM}$, very early in the morning, so there are few people there. We usually end up with a few hundred there by noon when we start handing out the fish. The reason why I include this is because a lot of people don't understand the significance of salmon to our cultures and identity. Every year we hold our breath wondering if our salmon will return. It's not just a matter of them returning and us eating salmon; you can get salmon at any store. It's the connections you have to space, to place, to family, to community when you 
gather for those communal fish days, and also the sharing of those foods. Those salmon that continually return to our rivers do so because of that connection that we have to them within our cultures and the spiritual connection we have to the spirits of the salmon.

So, it's not just a matter of connecting through the fishing of salmon, but also that we process salmon. I grew up processing miSaat, which is sockeye salmon in our language. I wasn't able to smoke salmon this year, but last year right next door to where I live in my community on Vancouver Island we did. My aunt and uncle live right beside me. This photo (Figure 4) is of my aunt and me preparing the smoke house, and you can see in in the bottom left, there is a bear also wanting to check out our smoke house. We have a lot of black bears on Vancouver Island. They don't bother you. They are usually there for what you're there for along the river, and that's to get the salmon.

Harvesting in our $h a-$ bouthee, in our traditional homelands: this photo (Figure 5) is myself with my sister on the right, in the hat. On the left, that's Nitanis Desjarlais, the one who created the video (with her husband John) that I showed a part of, earlier. We're harvesting devil's club. I like these photos, especially the one at the bottom left, because they really identify what place-based means and where we're going. We're walking up the stream to where there
Figure 3. Tseshaht Communal Fish Days

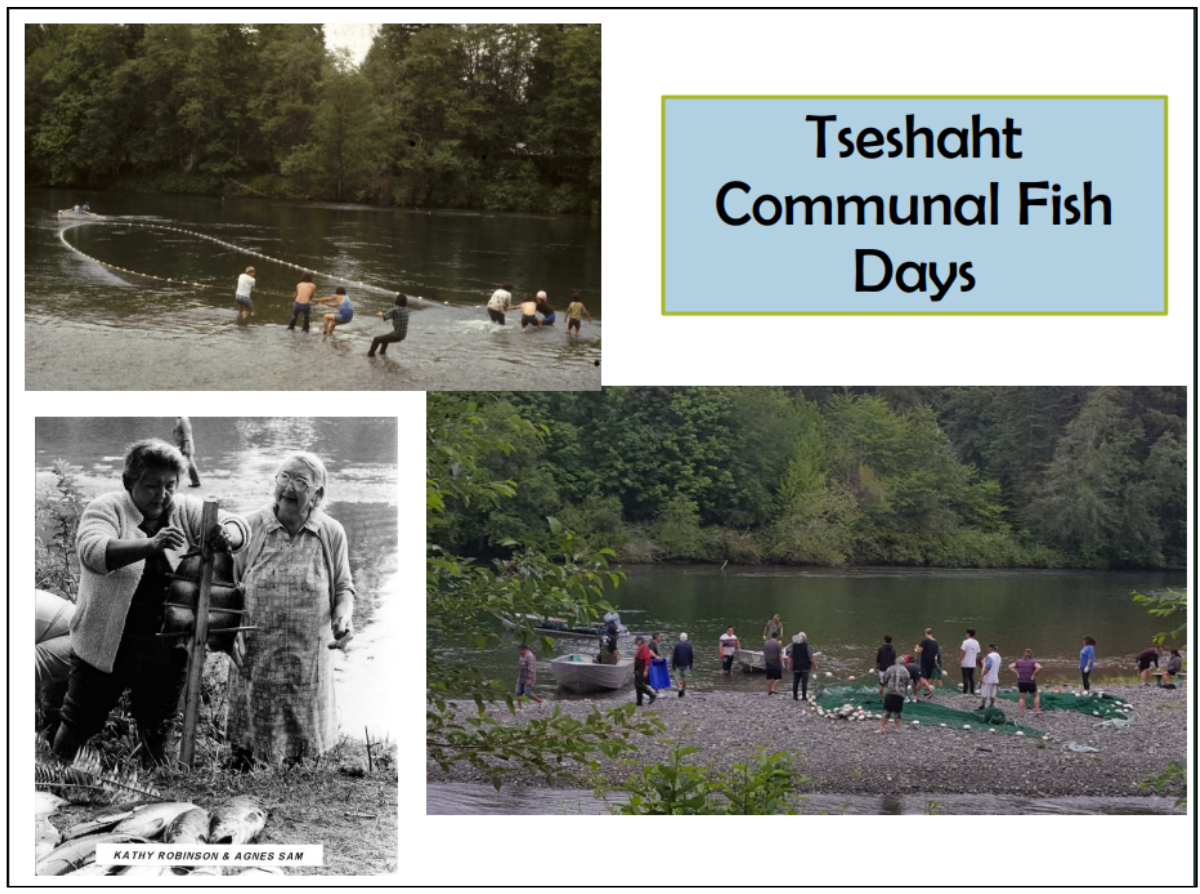

Figure 4. Preparing the Smoke House and Smoking MiSaat (Sockeye Salmon)

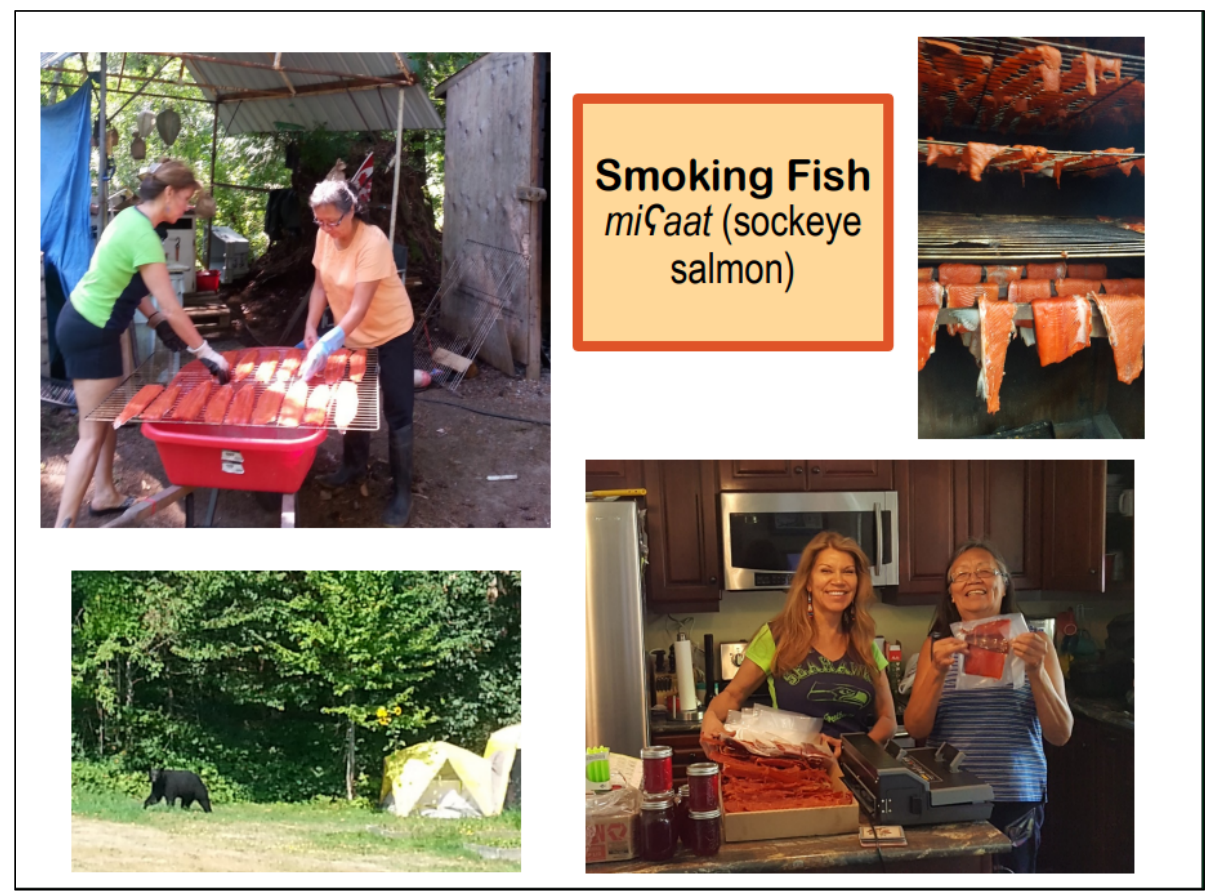


is a very large harvesting area. And so, you can really see those connections to place, to our

Figure 5. Harvesting in our Ha-houłhee (Traditional Homelands)

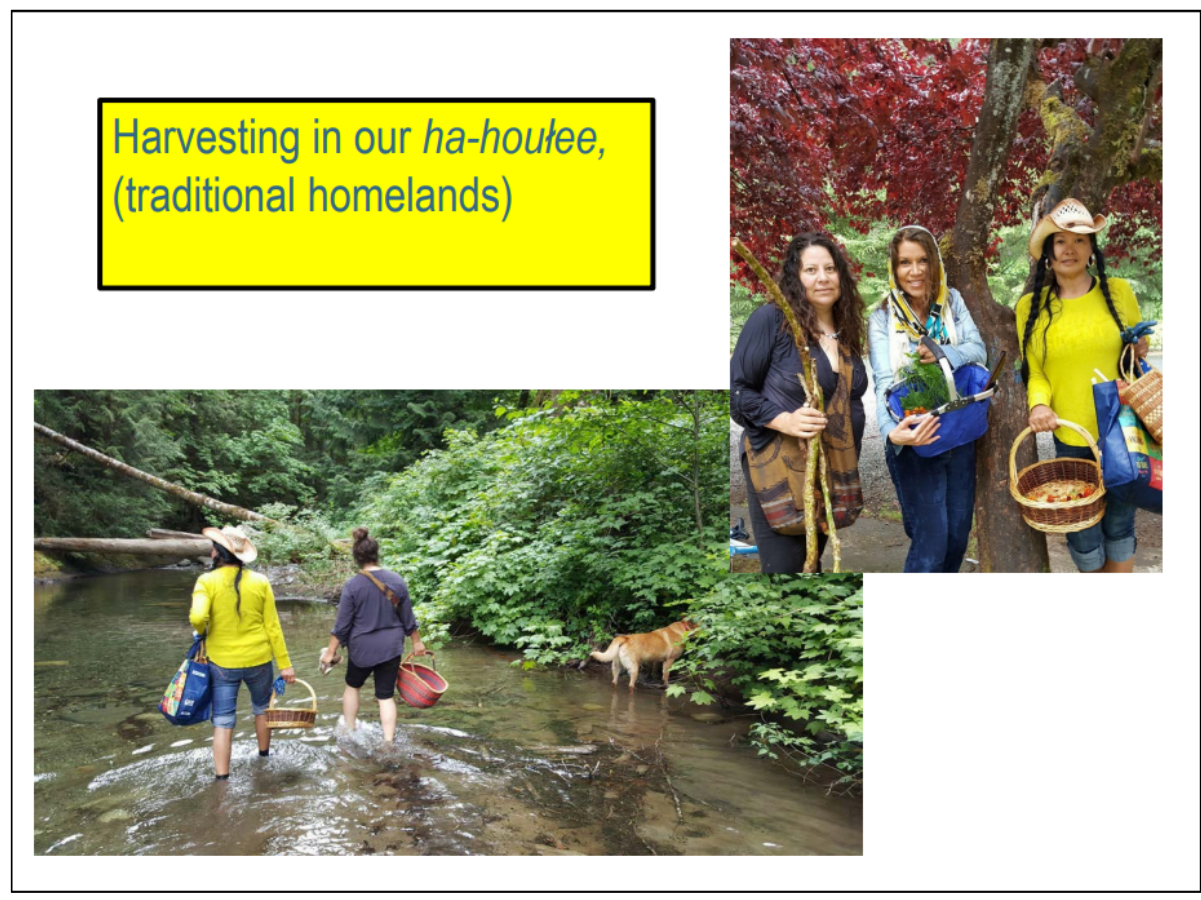

Figure 6. Harvesting Picmapt Fern and Fern Root

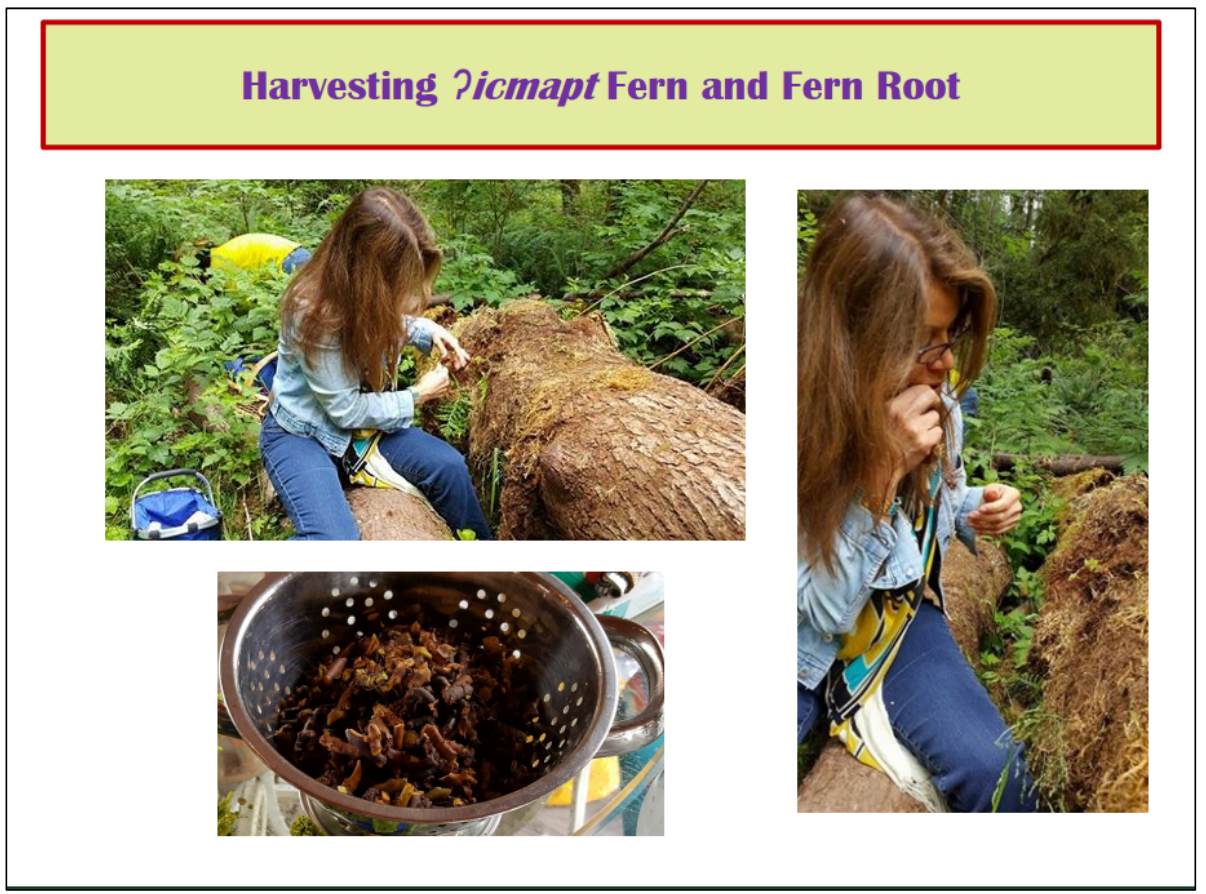

homelands or to our ha-houthee.

I have to say something about that photo

(Figure 5). This is in the afternoon after I don't know how many hours of harvesting. About two hours into our harvesting, it started to rain, and I said to my sister, this is how urbanized I've become-as soon as it started to rain, I said, "Are we gonna leave?" And she said, "Are you kidding? What do you mean are we're going to leave?" All I was worried about then was whether I was going to have fuzzy hair, like it matters, we're in the middle of the forest.

Picmapt in our language is fern. How many of you here are harvesters? Have any of you harvested the liquorice fern root? Oh my gosh, one of the best things you can count on. Great if you have a sore throat. Put it in some tea, steam it, it's wonderful to eat. This is us harvesting and eating. There is no way to pass by without eating some of it. And again, I like the photos (Figure 6) because they really show the connections that we have and how placebased our harvesting is.

This is another film project that Nitanis did: Nuu-chah-nulth Language Lessons on the Environment. ${ }^{2}$

${ }^{2}$ See the video at https://www.youtube.com/watch?v=jRR4-EA4dlM 
This is significant to my research, how indigenous place-based food systems are connected to language revitalization and traditional ecological knowledge. In this film project, Nitanis looked at understanding how you can learn and restore Nuu-chah-nulth language and how that plays an integral role in sustainability and restoring traditional ecological knowledge systems. So, this is a video she did with one of my late aunts, Linda Watts, who was the linguist in our community. It focuses on learning words that connect to the environment. It's a two-minute video, and I want to show a little bit of it because it isn't just about reconnecting this work that we're doing in our communities and reconnecting to our traditional food sources. It entails a lot more than that, and I think Nitanis really was able to demonstrate that in these film projects. This was particularly evident in placing our elders and traditional knowledge holders at the center of the work that we're doing. This was done here by working with one of my late relatives, my aunty Linda Watts, and really making sure that as we move forward in becoming selfdetermining and sustainable nations, that we're doing that with language revitalization as well.

\section{Figure 7. Harvesting Qawiisa, Salmonberry}

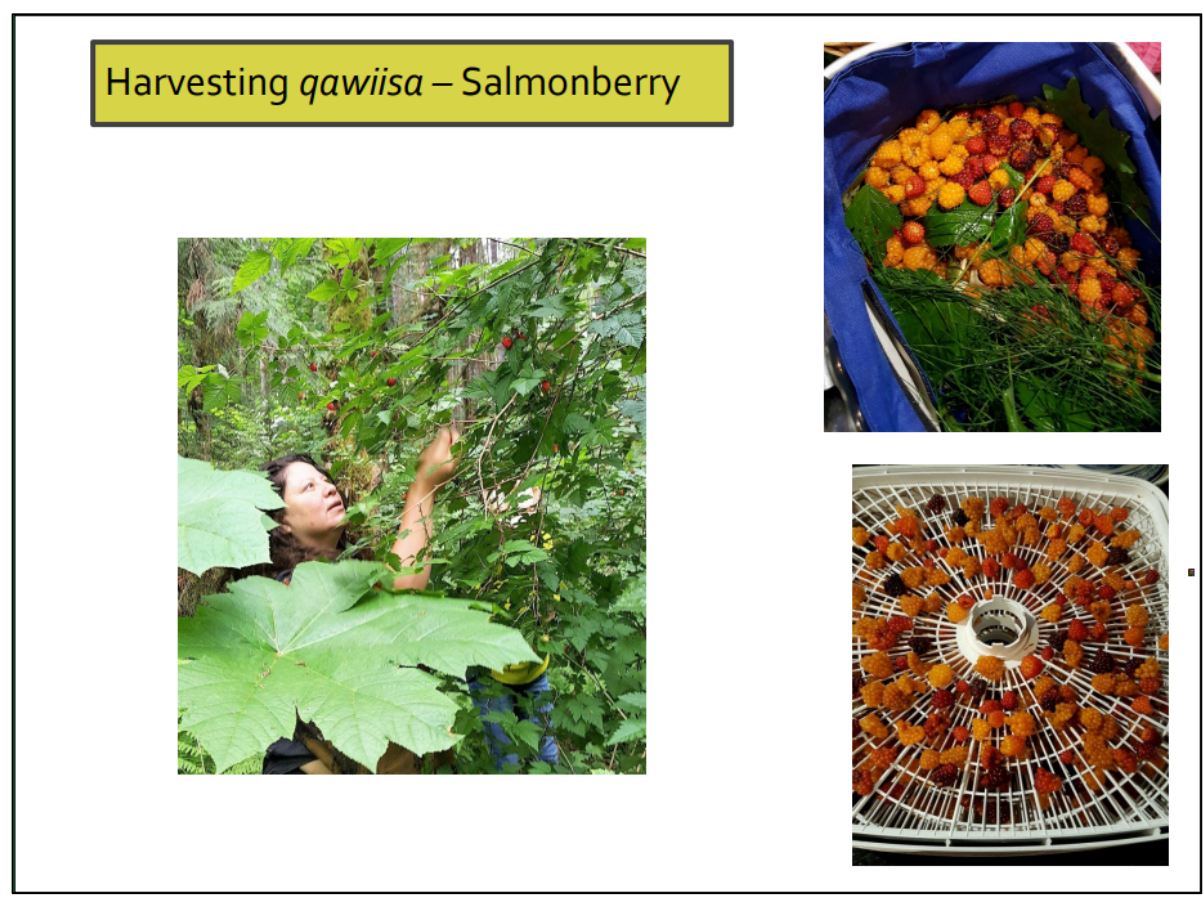

Figure 8. Harvesting Devils' Club

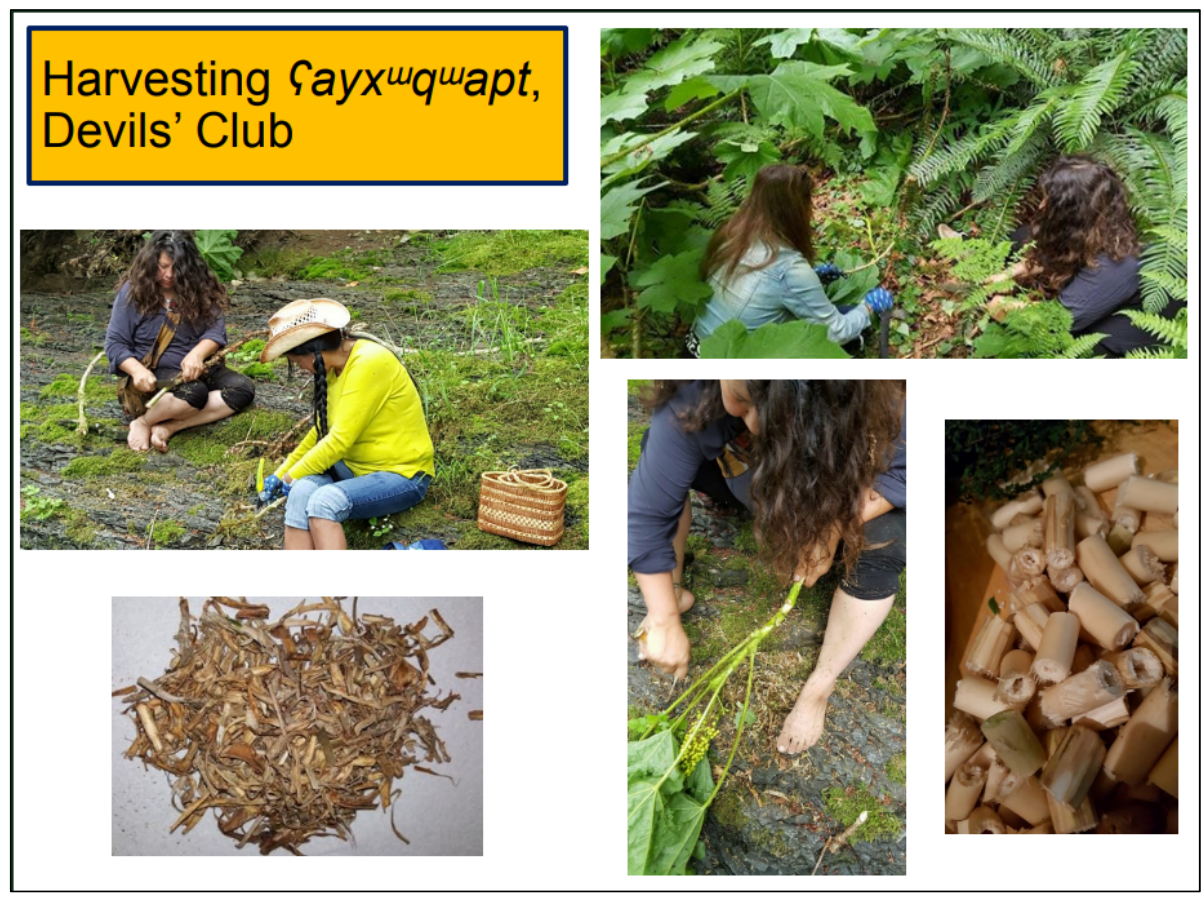

I don't know if you've noticed as I went through the presentation, but my slides do have our words. In the book that I'm working on related to revitalizing indigenous food traditions, I'm 
doing that as well because it's not only reconnecting to our language for our own purposes, but it's also sharing that with others so that others will also understand those words. Maybe those are the words that we can use instead of colonizers' words for some of these plants, places, and significant elements of our cultures.

So, these are another couple of photos that I took of harvesting qawiisa, salmonberry (Figure 7).

And this is, I'm not going to try to say our word for devils' club, it's very hard to say, but this is us harvesting devils' club (Figure 8). We did a couple of videos of the harvesting as well, but I can't figure out how to embed the video into my PowerPoint, so I can't show it.

\section{The Tseshabt Garden Project}

I'm going to end with this and then a short quote, but this is a garden, and it's not a traditional foods garden (Figure 9).

It's a garden that grows kale and spinach and carrots and squash. My sister created it in my community for one main reason. If you can see there on the right, there is a building. That building is a boarding school that shut down in the 1970s. When it was shut down, we removed that building and we built our Nuu-chah-nulth Tribal Council there. The council serves all 14 of our nations, but that space, that land that's there on the bottom right, where you see the garden, that was, and I put in air quotes, "a playground." Children never played in these schools. They were always under surveillance. They were always waiting to see if they would be the next victims of the people who abused them in these schools. There was a lot of violence and trauma that happened in these schools and to these children.

And so, when my sister decided she was going plant a garden there, I said to her, "Why are you planting the garden here of all places?" And she said, "But this is the whole idea of what I wanted to show, that when people, former students of these schools come here, they don't see that any more. What they see is my garden." So, I asked her, "Well, do you think the land can feel the pain the same way these children felt the pain?" And she says that the land, the plants, the animals, everything around here, they saw what happened. There is trauma in that land. We need to heal that land too. Believe me, I can't grow kale for the life of me although I've tried; her first year-she is into her third year with this garden-and it's like a Jurassic Park garden. That land needed to heal so badly that it's producing all of this bounty for us and for the people, some of whom went to those schools and experienced extreme hunger. Now here they are, eating this nutritious food and not only becoming nutritionally healthy, but also spiritually and emotionally healthy by removing those memories and replacing them with this beautiful space.

I'm going to end with this quote from one of our whaling chiefs, Chief Mexsis (Tom 
Happynook, 2001). I think it really does a nice summary of what I've covered in my presentation.

When we talk about indigenous cultural practices we are in fact talking about responsibilities that have evolved into unwritten tribal laws over millennia. These responsibilities and laws are directly tied to nature and is a product of the slow integration of cultures within their environment and the ecosystems. Thus, the environment is not a place of divisions but rather a place of relations, a place where cultural diversity and bio-diversity are not separate but in fact need each other... . This is cultural biodiversity; a practice which has been developed and nurtured over millennia; in the Nuu-chah-nulth language "Hishuk Tsawalk", everything is one, everything is connected. (p. 1)

Tleko. Thank you very much.

\section{References}

Atleo, E. R. [Chief Umeek]. (2005). Tsawalk: A Nuu-chah-nulth worldview. Vancouver: University of British Columbia Press. Corntassel, J. (2008). Toward sustainable self-determination: Rethinking the contemporary Indigenous-rights discourse. Alternatives, 33(2008). https://doi.org/10.1177/030437540803300106

Declaration of Nyéléni. (2007). Declaration of Nyéléni. Retrieved from https://nyeleni.org/spip.php?article290

Desjarlais, N., \& Rampanen, J. (Producers). (2013). Nuu-chah-nulth language lessons on the environment [Video]. Retrieved from https://www.youtube.com/watch?v=jRR4-EA4dlM

Desjarlais, N., \& Rampanen, J. (Producers). (2015). nuućaanuutathin we Are Nuu-chah-nulth [Video]. Shape Shyphter Studios. Retrieved from https://www.youtube.com/watch?v=0TaK8aaDumg

Happynook, T. M. (2001). Cultural biodiversity: Indigenous relationships within their environment. In R. S. Johnston \& A. L. Shriver (Compilers), Microbehavior and Macroresults: Proceedings of the Tenth Biennial Conference of the International Institute of Fisheries Economics and Trade (pp. 1-3). Corvallis, Oregon: IIFET. Retrieved from https://ir.library.oregonstate.edu/downloads/s4655h45p

Kimmerer, R. W. (2013). Braiding sweetgrass: Indigenous wisdom, scientific knowledge and the teachings of plants. Minneapolis, Minnesota: Milkweed Editions.

La Via Campesina. (n.d.). Home. Retrieved from https://viacampesina.org/en/

Morrison, D. (2011). Indigenous food sovereignty: A model for social learning. In H. Wittman, A. A. Desmarais, \& N. Wiebe (Eds.), Food sovereignty in Canada: Creating just and sustainable food systems (pp. 97-113). Halifax \& Winnipeg: Fernwood Publishing.

Patel, R. (2009). Food sovereignty. The Journal of Peasant Studies, 36(2009), 663-706. https://doi.org/10.1080/03066150903143079

Trauger, A. (2015). Putting food sovereignty in place. In A. Trauger (Ed.), Food sovereignty in international context: Discourse, politics and practice of place (pp. 1-12). New York: Routledge. https://doi.org/10.4324/9781315764429

Turner, N. J., Ignace, M. B., \& Ignace, R. (2000). Traditional ecological knowledge and wisdom of Aboriginal peoples in British Columbia. Ecological Applications, 10(5), 1275-1287. https://doi.org/10.1890/1051-0761(2000)010[1275:TEKAWO]2.0.CO;2

Wittman, H., Desmarais, A. A., \& Wiebe, N. (2010). The origins and potential for food sovereignty. In H. Wittman, A. A. Desmarais, \& N. Wiebe (Eds.), Food sovereignty: Reconnecting food, nature and community (pp. 1-12). Nova Scotia and Winnipeg: Fernwood Publishing. 